\title{
As contribuições da pedagogia do oprimido para a educação preventiva integral ${ }^{1}$
}

\author{
Las contribuciones de la pedagogía de la educación preventiva integral oprimida
}

\section{Contributions from the pedagogy of the oppressed to integral preventive education}

\author{
Araci Asinelli-Luz" \\ Michelle Popenga Geraim Monteiro* \\ Tatiane Delurdes de Lima-Berton ${ }^{* * *}$
}

\section{Resumo}

O presente artigo tem como objetivo enfatizar as contribuições da obra Pedagogia do Oprimido $(1979,1987)$ para a prática da Educação Preventiva Integral na infância e adolescência. Este artigo é uma pesquisa de cunho qualitativo e teórico, tendo como metodologia o estudo bibliográfico. No contexto social e educacional, em defesa de uma educação humanizadora, problematizadora com base na conscientização, colaboração e participação, Paulo Freire motiva discussões sobre a educação transformadora, ligando-a a possibilidades de ação e diálogo, que constrói e reconstrói o sujeito, pois, ao expressar-se por meio da palavra, o indivíduo cria/recria o mundo. É nesse processo que acontece a emancipação de forma coletiva, pois a educação está intrinsecamente ligada à transformação social. Por isso, acredita-se que pensar por esta ótica aumenta a chance concreta de uma realidade educativa melhor para crianças e adolescentes, especialmente aquelas que se encontram em situações de vulnerabilidade e/ou risco social, implicando em uma ordem ética com justiça social, em favor da minimização das violências (física, psicológica, moral, estrutural...) no âmbito escolar por meio de ações preventivas que valorizem a humanização.

Palavras-chave: Humanização. Paulo Freire. Prevenção. Transformação social.

Recebido em 28/02/2020 - Aprovado em 05/10/2020

http://dx.doi.org/10.5335/rep.v27i3.12377

Doutorado em Educação pela Universidade de São Paulo, mestrado em Educação pela Universidade Federal do Paraná. Professora associada 4 junto ao Departamento de Teoria e Prática de Ensino, Setor de Educação da Universidade Federal do Paraná. Atua na formação inicial e continuada de professores. Membro do PRONEA e da Comissão Nacional do PNLD pela SBPC e ex-secretária regional da SBPC no Paraná. E-mail: michellepgmonteiro@gmail.com; Orcid: https://orcid.org/0000-0001-5880-054

* Doutoranda em Educação pela Universidade Federal do Paraná, mestre em Educação pela Universidade Federal do Paraná. Atuou como professora colaboradora na Universidade Estadual do Paraná, campus Curitiba I, Escola de Música e Belas Artes do Paraná, cursos de Licenciatura em Música e Artes Visuais e na Prefeitura Municipal de Curitiba. E-mail: mizinhadobru@yahoo.com.br; Orcid: https://orcid.org/0000-0003-3058-8987

*** Doutoranda em Educação na Universidade Federal do Paraná; Mestre em Educação pela Universidade Federal do Paraná. Atuou na Prefeitura Municipal de Campo Largo como Educadora Social com crianças, adolescentes, jovens, adultos e idosos no Serviço de Convivência e Fortalecimento de Vínculos. E-mail: tati8lima@gmail.com; Orcid: https:// orcid.org/0000-0001-6653-2593 


\section{Resumen}

Este artículo pretende enfatizar las contribuciones de Pedagogia do Oprimido $(1979,1987)$ a la Educación Preventiva Integral en la infancia y la adolescencia. Este artículo es una investigación cualitativa y teórica, que utiliza el estudio bibliográfico como metodología. En el contexto social y educativo, en defensa de problematizar la educación basada en la conciencia, la colaboración y la participación, Paulo Freire motiva las discusiones sobre la educación transformadora, vinculándola a las posibilidades de acción y diálogo, que construye y reconstruye el tema, porque al expresar a través de la palabra, el individuo crea / recrea el mundo. Es en este proceso que la emancipación se lleva a cabo colectivamente, ya que la educación está intrínsecamente vinculada a la transformación social. Por lo tanto, se cree que pensar desde esta perspectiva aumenta las posibilidades concretas de una mejor realidad educativa, lo que implica un orden ético con justicia social, a favor de minimizar la violencia en el entorno escolar a través de acciones preventivas que valoren la humanización.

Palabras clave: Humanización. Paulo Freire. Prevención. Transformación social.

\section{Abstract}

This article aims to emphasize the contributions of Pedagogia do Oprimido $(1979,1987)$ to Integral Preventive Education in childhood and adolescence. This article is a qualitative and theoretical research, using bibliographic study as methodology. In the social and educational context, in defense of na problematizing education based on awareness, collaboration and participation, Paulo Freire motivates discussions about transformative education, linking it to possibilities of action and dialogue, which builds and reconstructs the subject, because by expressing himself if through the word, the individual creates / recreates the world. It is in this process that emancipation takes place collectively, as education is intrinsically linked to social transformation. Therefore, it is believed that thinking from this perspective increases the concrete chance of a better educational reality, implying an ethical order with social justice, in favor of minimizing violence in the school environment through preventive actions that value humanization.

Keywords: Humanization. Paulo Freire. Prevention. Social transformation.

\section{Introdução}

O ser humano, em sua existência, busca pela evolução. Porém, há manifestações de vulnerabilidade que podem provocar dificuldades e/ou riscos para seu desenvolvimento. Considera-se que, por ser vulnerável, há influências internas e externas advindas de deficiências de múltiplas naturezas, aflições, dificuldades sem defesa. Há fatores que influenciam o contexto em que está inserido, como, por exemplo, a globalização: um sistema socioeconômico que não possui oposições, oportunizando que não sejam construídas referências de apoio às classes menos favorecidas. Nessa perspectiva, a vulnerabilidade se manifesta de muitas maneiras, em diversas fontes que condicionam a existência (ROMERO, 2009).

Na esfera biológica, o ser humano está sujeito a todos os tipos de doenças, em que, com o aumento da longevidade, os problemas sociais se agravam - há prevalência de doenças em idades mais avançadas e em classes de menor escolaridade. 
O aumento descontrolado da população humana, falta do desenvolvimento de autoconsciência dos sujeitos devido a escassa escolarização das classes populares; tendência de deixar o atendimento médico da população no viés da privatização; oferta de serviços públicos deficientes/inexistentes; grande concentração da população nas cidades, aumentando a fonte de conflitos. Em relação às esferas psicológica e social, existem perturbações associadas à depressão, ansiedade, estresse e de reflexo do sistema orgânico, a primazia de interesses materiais dominantes no sistema social acarretam em sujeitos consumidores e produtores de "coisas"; há a produção massiva; descuido do ambiente físico; estímulo à aquisição de bens de consumo e divertimentos alienantes, luta pela sobrevivência, direitos humanos violados, bem como a exposição a diversos tipos de violência (ROMERO, 2009).

Tratando-se do desenvolvimento humano e das influências que sofre direta e indiretamente, as crianças e adolescentes se tornam ainda mais vulneráveis. A questão da violência, que está disseminada na sociedade contemporânea, talvez seja hoje um dos principais problemas que deve ser superado pelas por meio das mais diversas políticas públicas seus programas e ações. Dentre tantas violências que assombram a realidade e impedem a garantia dos direitos fundamentais de crianças e adolescentes, há, por exemplo, as de natureza psicológica, cujas características envolvem as condutas que afetam o âmbito psicológico, causando abalo emocional e diminuição da autoestima, devido promoção de constrangimentos, humilhações, manipulações e ameaças. A de natureza moral envolve casos de calúnia, injúria e difamação, enquanto a violência de natureza física atinge a integridade ou saúde corporal. Ainda, a violência de natureza sexual envolve as agressões e abusos que obrigam a criança/adolescente a manter ou a participar de relação sexual. Além dessas violências, há também as discriminatórias, estrutural, de negligência, abandono, bullying, cyberbullying, dentre outras (MONTEIRO; LIMA-BERTON; ASINELLI-LUZ, 2019).

Tratando-se de vulnerabilidades, a infância e a adolescência são marcadas por momentos de fragilidades e dependência humana, o que as torna socialmente e emocionalmente fragilizadas. Nesse sentido, considerando os desdobramentos que envolvem as vulnerabilidades e desigualdades presentes, diversas são as violências que implicam na infância e na adolescência, destacando as inúmeras violações de direitos por que passam, a considerar as violências intrafamiliares, sociais, estruturais, entre pares e tantas outras (LIMA-BERTON; MONTEIRO; ASINELLI-LUZ, 2019). Porém, em relação à escola, pesquisadores (LOPES NETO, 2011; MONTEIRO, 2017b; TOGNETTA, 2013; SALMIVALLI, 1999, 2010, 2014) têm se 
preocupado com o aumento das violências e a dimensionalidade que elas atingem entre os estudantes.

Não se trata de um assunto novo, nem tampouco de fácil compreensão e intervenção, principalmente em se tratando de crianças e adolescentes. Os males que as violências acarretam devem ser contestados em qualquer situação, pois o fato de dependerem dos adultos e serem frágeis e vulneráveis justifica mais, e não menos, investimentos em medidas de prevenção e proteção, sendo assim, nenhuma violência contra crianças é justificável e toda ela pode ser evitada. Para Pinheiro (2010, p. 15), a exposição à violência "pode gerar inabilidades sociais que podem perdurar por toda a vida e também problemas emocionais e cognitivos, obesidade e comportamentos de risco em relação à saúde [...]”.

Refletir sobre o desenvolvimento humano na infância e na adolescência e, em especial aquelas em situação de vulnerabilidade e/ou risco social, demanda da discussão e da prática de uma educação emancipatória e de constante provocação da consciência crítica social, uma vez que as crianças e adolescentes precisam tornar-se agentes de transformação, não apenas do contexto em que estão inseridas, mas, principalmente, das próprias vidas. Na busca por referenciais que auxiliem e inspirem na promoção do desenvolvimento e dos direitos humanos, há as grandes contribuições do educador brasileiro Paulo Freire. Dentre tantas obras instigadoras, Pedagogia do Oprimido (1987) foi escolhida como base para o presente estudo, porque é aquela que se identifica com o chamamento à lucidez para a produção de uma cultura de liberdade e transformação social, tendo a educação como problematizadora e, como suporte, a leitura do mundo e o desenvolvimento de uma emancipação e uma consciência crítica social. Em meio a um contexto caracterizado por desigualdades e opressões que foram marcados pelas condições históricas sociais e humanas, é uma obra que mobiliza sentimentos e ações em prol da cidadania por via da Educação. Neste estudo, têm-se a criança na condição de oprimida, que em meio a tantos opressores (que podem estar na família, na escola, na comunidade ou em outros espaços de interação), busca-se o seu desenvolvimento pleno e a garantia dos direitos fundamentais.

Por meio da leitura dessa obra, pode-se fazer uma reflexão acerca das desigualdades e violências, físicas, sociais e estruturais, ocasionadas no âmbito da infância e adolescência, em todas as camadas sociais brasileiras e que são manifestadas por meio de situações cotidianas que são vivenciadas, em especial, aquelas crianças e adolescentes que são desprovidas socialmente, que se encontram em um contexto de vulnerabilidade, risco social. Assim, há um consenso por um movimento que 
busca a valorização da justiça social, pois estas lutam por melhorias na qualidade de vida e na distribuição de oportunidades para equalizar a população e pelas discussões preventivas, fortalecendo o desenvolvimento humano no que diz respeito a mudanças de atitudes e condutas em prol da valorização do ser humano. Em se tratando de vulnerabilidades, a infância e a adolescência são marcadas por momentos de fragilidades e dependência humana, o que as torna social e emocionalmente fragilizadas. Nesse sentido, considerando os desdobramentos que envolvem as vulnerabilidades e desigualdades presentes, diversas são as violências que implicam na infância e na adolescência, destacando as inúmeras violações de direitos por que passam, a considerar as violências intrafamiliares, sociais, estruturais, entre pares e tantas outras (LIMA-BERTON; MONTEIRO; ASINELLI-LUZ, 2019). Porém, em relação à escola, pesquisadores (LOPES NETO, 2011; MONTEIRO, 2017b; TOGNETTA, 2013; SALMIVALLI, 1999, 2010, 2014) têm se preocupado com o aumento das violências e a dimensionalidade que as mesmas atingem entre os estudantes.

Depois da família, a escola é o segundo ambiente de maior convivência entre pares e de manifestações de experiências coletivas, de formação de identidades e de aprendizado cognitivo e social. Por isso, o ambiente escolar deve proporcionar aos estudantes nele inseridos, o desenvolvimento humano necessário. A escola, enquanto instituição social, promotora da socialização, reflete os conflitos e as diferenças que surgem por meio dos tipos e das possibilidades de relacionamentos existentes e repercute as transformações que acontecem no mundo, lidando com diferentes implicações. O preparo dos estudantes para superarem as adversidades que aparecem neste percurso por meio de ações preventivas é fundamental, em especial na formulação de soluções para a resolução de conflitos (DESSEN; POLONIA, 2007).

Diante disso, acredita-se que a chave para a efetivação de ações preventivas eficazes é a educação transformadora, com o foco na busca da construção do sujeito. Sendo assim, essas considerações conduzem o presente artigo para a seguinte questão norteadora: de que forma a Pedagogia do Oprimido de Paulo Freire pode contribuir com a prática de uma Educação Preventiva Integral na infância e adolescência? Pensa-se na perspectiva da Pedagogia Social, de modo a construir diálogo e transformação social por meio da Educação - essa, humana e humanizadora.

E para o presente artigo, assume-se a dimensão humanizadora de prevenção, indicando-a como processo de conhecimento, crescimento e desenvolvimento do ser humano como um todo. Evidenciam-se, neste estudo, a criança e o adolescente, com as suas condições biopsicossociais, em universos históricos, políticos, econômicos e sociais, refletindo principalmente sobre as que estão em situações de vulnerabi- 
lidade e/ou risco social. Pensa-se na perspectiva da Pedagogia Social, com objetivo geral de salientar as contribuições da Pedagogia do Oprimido de Paulo Freire para a prática de uma Educação Preventiva Integral na infância e adolescência. Desse modo, tem-se como objetivos específicos: reforçar a importância dos estudos de Paulo Freire para a promoção da educação problematizadora/transformadora; evidenciar a Educação Preventiva Integral para o desenvolvimento humano na infância e adolescência; relacionar a Pedagogia do Oprimido à prática da Educação Preventiva Integral; reconhecer a importância da prevenção e do diálogo no processo educativo da criança e do adolescente.

Portanto, o artigo compõe-se de um estudo que abrange a educação transformadora, problematizadora, humanizadora de Paulo Freire, capaz de inspirar educadores e educandos a construírem juntos uma relação horizontal, a fim da promoção da educação preventiva integral e que, consequentemente, auxilie na minimização das violências sofridas na infância e adolescência. Trata-se de um estudo qualitativo e teórico, na perspectiva freiriana. Nesse âmbito, a relevância do estudo na área educacional justifica-se em razão da produção de conhecimento no campo teórico-metodológico para a comunidade escolar e científica, como forma de reflexão sobre as relações sociais, além de tornar-se um meio de suscitar discussões entre sociedade acadêmica e demais agentes inseridos no campo da educação. Ademais, reforça a importância da garantia e preservação dos direitos fundamentais das crianças e adolescentes, na prevenção de violências e, na atuação de retirá-las da condição de oprimidas, na busca de oportunizar o seu desenvolvimento pleno.

\section{A pedagogia do oprimido no contexto da educação preventiva integral: infância e adolescência}

O conhecimento nas áreas da infância e adolescência tem ganhado destaque e notoriedade nos últimos tempos e trazem diversas possibilidades de atuação em relação à proteção e aos direitos fundamentais desses sujeitos. Por serem considerados indivíduos vulneráveis, as crianças e adolescentes estão mais suscetíveis às violências, em uma condição de oprimidas. E essas fragilidades podem relacionar-se à submissão em relação ao adulto, em que este pode comportar-se como opressor, da subestimação das potencialidades na infância e na adolescência, bem como da não importância dessas fases para a construção da identidade e da sociabilidade na condição de seres humanos. Essas fragilidades envolvendo crianças e adolescentes 
se aproximam do pensamento de Paulo Freire (1987, p. 16), ao destacar o processo de desumanização envolvendo o opressor, a opressão, as violências, as injustiças sociais que distorcem a real humanização: "a desumanização, que não se verifica apenas nos que têm sua humanidade roubada, mas também, ainda que de forma diferente, nos que a roubam, é distorção da vocação do ser mais". Nesse âmbito, é necessário realizar reflexões sobre as violências sociais e estruturais, sobre as desigualdades que são geradas por fatores históricos, sociais e econômicos, assim como dos caminhos a se promover a prevenção e, consequentemente, a justiça e a igualdade (MONTEIRO; LIMA-BERTON; ASINELLI-LUZ, 2018).

Santomé (1998, p. 131-135) expressa:

As culturas ou as vozes dos grupos sociais minoritários e/ou marginalizados, que não dispõem de estruturas importantes de poder costumam ser silenciadas, ou mesmo estereotipadas e deformadas para anular suas possibilidades de reação. Entre essas culturas ausentes podemos destacar as culturas infantis e juvenis. [...]. Uma instituição escolar que não conseguir vincular essa cultura juvenil que os jovens vivem tão apaixonadamente em seu ambiente, em sua família, com seus amigos e amigas, etc., com as disciplinas mais acadêmicas do currículo, está deixando de cumprir um objetivo assumido por todo mundo, que é o de ligar as instituições escolares ao ambiente, como única maneira de ajudar os estudantes a melhorar a compreensão de suas realidades e a comprometer-se com sua transformação.

As reflexões sobre os aspectos sociais, econômicos e educacionais presentes na sociedade, trazem a discussão de dois aspectos importantes que Paulo Freire em sua obra Pedagogia do Oprimido aborda: de um lado a educação bancária, que se mostra por meio da opressão da classe dominante em detrimento a humanização; e do outro, a educação libertadora, que enfatiza a transformação do sujeito, por meio da reflexão crítica social (MONTEIRO; LIMA-BERTON; ASINELLI-LUZ, 2018). Por isso, a violência presente no ambiente escolar, local no qual acontece grande parte das interações e socializações entre pares, também ganha relevância nas pesquisas, pois é considerado um problema social que tem gerado preocupações em diversos setores sociais devido a sua gravidade e disseminação.

A educação bancária transforma o processo educativo em um simples depósito de informações e considera o estudante como passivo e inerte. Em contrapartida, a educação libertadora visa ao exercício da ação educativa como liberdade, constituindo-se de reflexões críticas, éticas e solidárias, em que os sujeitos do processo educacional trabalham em respeito e diálogo. Nesse processo, a medida que o sujeito reconhece a sua capacidade de leitura do mundo e de adaptação às demandas sociais, há possíveis transformações. Por isso, há a necessidade da construção da 
liberdade ao lado da generosidade, para a assimilação da democracia em detrimento da obediência e do medo (MONTEIRO; LIMA-BERTON; ASINELLI-LUZ, 2018).

O processo de superação da opressão e da violação dos direitos humanos deve nascer dos oprimidos, sendo esse um parto doloroso, pelo qual o oprimido que quiser se libertar terá de passar, em vista de não ser mais nem oprimido, nem opressor, mas um sujeito "livre". Para isso acontecer, os oprimidos precisam se dar conta de sua realidade para, então, lutarem pela transformação da opressão, da violação (MAGRI, 2012, p. 51).

Como fator fundamental para antecipar demandas dos escolares, a prevenção se faz necessária, no sentido de evitar que o problema seja instaurado. Prevenção se relaciona com acolhimento do sujeito em sua história, em seu contexto, em suas necessidades, permitindo que seja seu próprio protagonista, atuando diante dos desafios, a fim de enfrentá-los. A perspectiva da Educação Preventiva Integral reforça o diálogo como mediador nas interações sociais, desenvolvendo a empatia e reforçando o processo educativo para a liberdade e respeito ao ser humano (ASINELLI-LUZ, 2014).

Como um eixo central para a promoção das relações e construções de visões de mundo, é necessário atentar-se à efetivação da prática docente como caráter filosófico que resgata o sujeito oprimido, que vivencia as imposições do sistema e só consegue se libertar à medida que pensa sobre a ação. Para isso, destaca-se a autonomia na prática do educador, para que ele consiga um exercício de docência por meio do estabelecimento de relações mais próximas do educando, não seguindo apenas um currículo, mas percebendo a diversidade de seus educandos, organizando-se sempre na renovação da sua própria prática (refazendo-se de suas vivências). Destaca-se que o (a) educador (a), em seu exercício, requer uma profunda compreensão sobre a reflexão da ação, possibilitando que se perceba no contexto, na realidade que vive e que deve transformar, bem como da sua relação direta com 0 educando (FREIRE, 1996; CARRARO; CURY, 2015).

O conceito de tensão dialética aplica-se na sequência de ações que acontecem no processo de aprendizagem - aprender, apreender, reaprender, incorporar, avançar - e é nesse processo que ocorrerá a construção do real, que exige uma ressignificação constante do papel desempenhado pelo professor que, antes de ensinar, aprende (CARRARO; CURY, 2015, p. 93).

Em relação ao ser humano, leitura crítica e mediação, o docente aprende a aprender, tornando o saber como algo acessível, que transforma, que promove formação, que transcende e que modifica o outro. A sua prática torna-se um processo de conhecimento em nível sistemático, implicando sabedoria à medida que se ensina e aprende. Logo, o educador e o educando são sujeitos em constante formação. 
Para isso, Paulo Freire (1987) evidencia como ponto de partida para a compreensão da complexidade do ser humano o diálogo, em um processo democrático e crítico. Nesse contexto, o diálogo é a ferramenta de aproximação e essência do indivíduo, pois é ele que constrói vínculos, desenvolve sentidos, oportuniza novas aprendizagens, forma cidadãos e promove a transformação social.

Não há diálogo, porém, se não há um profundo amor ao mundo e aos homens. Não é possível a pronúncia do mundo, que é um ato de criação e recriação, se não há amor que o funda. Sendo fundamento do diálogo, o amor é, também, diálogo. Daí que seja essencialmente tarefa de sujeitos e que não possa verificar-se na relação de dominação (FREIRE, 1987, p. 45).

Assim, destaca-se o diálogo como um mecanismo de oportunidade de interação, como uma das formas de práticas de prevenção das violências. Sendo assim, pode-se destaca a Cultura da Paz como um dos modelos de enfrentamento das violências, uma vez que ela enfatiza a promoção do diálogo como forma de resolução de conflitos. Assim, na discussão sobre as violências, a Cultura da Paz aparece como fundamento e metodologia, sendo alicerce e base para as iniciativas de prevenção do fenômeno, se enquadrando em um modelo de educação preventiva integral, já que esta prioriza a humanização e a valorização do ser humano. Portanto, a ênfase na sistematização nas relações de paz no interior das escolas, bem como o aprofundamento nesta temática, é fundamental para melhorar e aprimorar os programas e projetos de minimização e de prevenção. Partindo desses pressupostos de prevenção, pode-se dizer que a construção da paz está relacionada ao processo de práticas de convivências não violentas, dando ênfase aos valores pessoais e sociais, estabelecidos nos pressupostos do diálogo, do respeito e da diversidade. A partir do pensamento de Paulo Freire, demonstra-se uma postura de generosidade e compreensão diante das diferenças sociais e culturais, tolerância e respeito à leitura de mundo do outro (SALLES FILHO, 2008; MONTEIRO, 2017b; MONTEIRO; LIMA-BERTON; ASINELLI-LUZ; 2018).

Nesse sentido, a Educação Preventiva Integral busca a promoção da formação humana a médio e longo prazo, pois prioriza a mudança de atitudes e condutas, uma vez que uma intervenção momentânea pode apenas alterar por um curto espaço de tempo a percepção do problema (ASINELLI-LUZ, 2000). A prevenção exige planejamento a partir dos conhecimentos históricos e culturais do meio social de que se está inserido, bem como pressupor as necessidades reais do ser humano, valorizando a vida e priorizando as instâncias imediatas de necessidades básicas humanas (ASINELLI-LUZ, 2000). Quem inicia o processo de avanço das violências vividas na escola não são as crianças ou adolescentes que se envolvem, mas todo 
aquele que detém o poder de atuação e decisão neste meio e/ou sua morosidade, impedindo que a cultura da prevenção, do chegar antes, insere-se na escola como um instrumento de desenvolvimento da cidadania (ASINELLI-LUZ, 2000).

Não haveria oprimidos, se não houvesse uma relação de violência que os conforma como violentados, numa situação objetiva de opressão. Inauguram a violência os que oprimem, os que exploram, os que não se reconhecem nos outros; não os oprimidos, os explorados, os que não são reconhecidos pelos que os oprimem como outro. Inauguram o desamor, não os desamados, mas os que não amam, porque apenas se amam. Os que inauguram o terror não são os débeis, que a ele são submetidos, mas os violentos que, com seu poder, criam a situação concreta em que se geram os "demitidos da vida", os esfarrapados do mundo. Quem inaugura a tirania não são os tiranizados, mas os tiranos. Quem inaugura o ódio não são os odiados, mas os que primeiro odiaram. Quem inaugura a negação dos homens não são os que tiveram a sua humanidade negada, mas os que a negaram, negando também a sua. Quem inaugura a força não são os que se tornaram fracos sob a robustez dos fortes, mas os fortes que os debilitaram (FREIRE, 1979, p. 45).

Nesse sentido, vale ressaltar a importância da prevenção humanizadora na escola, auxiliando no processo de reversão da alienação dos jovens e, em contrapartida, promover o desenvolvimento de uma consciência crítica sobre as problemáticas do mundo e as que o circundam. Assim, "a prevenção pode, então, ser entendida como uma forma de fortalecimento das relações inter e intrapessoais (professor-aluno, aluno-aluno e cada um consigo mesmo) no âmbito da sala de aula e da escola, a partir de um clima adequado de crescimento e valorização da vida" (ASINELLI-LUZ, 2000, p. 57).

Enfrentar desigualdades, riscos e vulnerabilidades sociais exige conhecimentos e estudos voltados à compreensão de fatores econômicos, socioculturais, psicológicos, políticos e de contextualização comunitária, a fim de elaborar e desenvolver metodologias de ação coletiva para a superação de problemáticas. Paulo Freire (1996) apresenta que essas relações estabelecidas pelos sujeitos permitirão a construção coletiva dos conhecimentos, havendo mudanças significativas para o exercício da criticidade, da dialogicidade e do potencial transformador.

Em conexão com a importância do diálogo e da aproximação do sujeito com suas realidades, a Educação Preventiva Integral busca a construção individual, social, com incentivo à troca de experiências, às interações. Como o foco é o sujeito, suas relações, sua história de vida, retira-se a centralidade nos problemas e exaltam-se as potencialidades, o modo de compreensão e leitura de mundo, a consciência das ações e da condição de vida, bem como o planejamento e a construção de projetos de vida, de protagonismos da própria trajetória. Por haver intencionalidade, estimula-se o desenvolvimento humano por meio de suas condições biológicas, 
físicas, sociais, políticas, culturais e essenciais, a fim de prepará-lo para o enfrentamento e a superação de possíveis entraves em sua trajetória (ASINELLI-LUZ, 2014; LIMA, 2017a; ALMEIDA; ARONE, 2017). Ao encontro do caráter dialógico, transformador, crítico e político de Freire (1987), reforça-se que a educação precisa provocar o senso crítico, as interações sociais, a reflexão, a autonomia, sendo que, “ao contrário da bancária, a educação problematizadora responde a essência do ser da consciência, que é sua intencionalidade, nega os comunicados e existência à comunicação, baseada no diálogo" (1987, p. 77).

A educação não se direciona apenas à ampliação do conhecimento, mas promove à emancipação, a autonomia, a provocação de uma intencionalidade que poderá beneficiar o plano individual e coletivo. Sua notoriedade e impacto extrapolam os muros escolares e desenvolvem o senso crítico, político e cidadão, além de esferas profissionais, culturais, esportivas, de saúde e lazer (TRILLA; GHANEM, 2008). Por então se envolver na amplitude do ser e de suas características próprias e de projeção de vida, a escola deve destacar o trabalho com as problemáticas transversais e, neste caso, pode-se incluir as violências de forma geral, abordando as temáticas com a busca de informações em fontes variadas, sistematizando o conhecimento e organizando projetos que sejam contextualizados à realidade vivida.

Para o educador-educando, dialógico, problematizador, o conteúdo programático da educação não é uma doação ou uma imposição - um conjunto de informes a ser depositado nos educandos, mas a devolução organizada, sistematizada e acrescentada ao povo, daqueles elementos que este lhe entregou de forma inestruturada (FREIRE, 1979, p. 98).

A criança, o adolescente, o ser humano em si se constitui de processos, tempos e contextos que precisam ser observados na grande concepção do que é o desenvolvimento humano (BRONFENBRENNER, 2011), por isso, torna-se fundamental que o processo da educação seja voltado para esses sujeitos e suas realidades. $\mathrm{O}$ educador, na sua posição horizontal junto ao educando, precisa estimular o diálogo, a intencionalidade, a reflexão, a consciência das ações e das relações para evitar situações de vulnerabilidade e/ou riscos sociais e que possam prejudicar seu desenvolvimento.

O ponto de partida da educação libertadora se caracteriza exatamente com essa dimensão da relação do homem com a realidade em que vive pelo fato de que o processo educacional deve ser a partir da realidade dos educandos, e não a partir das ideias do professor. O mundo agora não é algo sobre o que meramente se fala com falsas palavras, que se tem noções de partes, mas é agora o mundo mediador dos sujeitos no processo educacional (MAGRI, 2012, p. 52). 
A abordagem realizada entre o educador e educando, com olhar problematizador, traz à tona a escuta e o diálogo. Essa dinâmica exige do corpo escolar uma mudança no olhar, uma forma de repensar a educação a partir das demandas sociais que surgem. O diálogo torna-se um fator fundamental para todo o processo. $\mathrm{Na}$ busca pela justiça social, pela sua compreensão dentro dos contextos da sociedade, se faz necessário refletir sobre as demandas e potencialidades de cada sujeito. Compreender valores, culturas, realidades fazem com que o sujeito compreenda os processos de construção da sociedade, da cidadania e da democracia (MONTEIRO; LIMA-BERTON; ASINELLI-LUZ, 2019).

O diálogo é a essência da emancipação humana, é sempre uma relação de iguais midiatizados pelo mundo. Mas, se dizer a palavra verdadeira, que é trabalho, que é práxis, é transformar o mundo, dizer a palavra não é privilégio de alguns homens, mas direito de todos os homens. Precisamente por isto, ninguém pode dizer a palavra verdadeira sozinho, ou dizê-la para os outros, num ato de prescrição, com o qual rouba a palavra aos demais (FREIRE, 1987, p. 78).

Dialogar requer esforço, atenção e dedicação dos envolvidos. É um canal de exploração de percepções, pensamentos e novas perspectivas. Diálogo é também prevenção, é uma atitude responsável e humanizadora: ele auxilia na compreensão de quem é o ser humano, de como se desenvolve, atribuindo dessa maneira, conhecimento sobre seus comportamentos (LIMA, 2017a). O educador, presente conscientemente no âmbito escolar precisa auxiliar o educando na superação das problemáticas relacionadas às vulnerabilidades e riscos sociais. Não apenas focando no profissional, mas principalmente no sujeito: é preciso observar o educando como a solução, ao invés de ser o problema.

À medida que o ser humano reconhece a sua capacidade de adaptar-se às demandas que surgem na sociedade e pensa para melhorar suas operações, ocorre então a possibilidade de transformação. A educação, por sua vez, reforça o pensamento sobre a maneira de assimilar a constituição da realidade, da cidadania, da democracia, pois, se o autoritarismo não abre espaço, não há como se desenvolver a liberdade. Assim, só haverá possibilidades à medida que a liberdade for construída ao lado da autoridade e da ética ao invés da obediência e do medo. Freire (2000) reforça a tarefa primordial de zelo e afetividade ao praticar a liberdade com autoridade e sem autoritarismo, educando e se educando (aceitação respeitosa) à medida que interagem na perspectiva democrática e ética.

É preciso trabalhar em uma visão ampliada do ser. E trabalhar na perspectiva da Educação Preventiva Integral reforça que a prevenção se trata do "chegar 
antes", conhecer o sujeito e atuar antecipadamente ao problema. É estimular o desenvolvimento pleno e suas relações sociais para que seja possível suprir suas demandas e prevenir fenômenos que prejudiquem sua evolução. Na condição de seres humanos, precisa-se reconhecer a existência. Freire $(1987,2000)$ destaca que desde a infância a criança precisará aprender que a autonomia se autenticará no respeito à autonomia dos outros. Para isso, os pais não devem aplicar-se à tirania da liberdade, na qual pensam e permitem que seus filhos sejam livres sem limites. Provocar a leitura crítica potencializa o fazer pedagógico, envolvendo a organização de classes populares para a reinvenção da sociedade. É lutar por uma problemática com a legitimidade de um sonho ético, político e de superação de uma realidade injusta. Surge então, a necessidade do trabalho do educador progressista, capaz de, humildemente, auxiliar nos desafios, a fim de possibilitar a criticidade mediante a realidade política, histórica e social da presença no mundo. Por fim, atuando em prol uma Educação Preventiva Integral, Paulo Freire, educador humanizado e humanizador, instiga a reflexão de apostar e tornar possível o empoderamento do sujeito e de seus grupos, permitindo a intervenção no mundo para transformá-lo e não apenas para mantê-lo da maneira como está.

\section{Considerações finais}

A educação, como oportunidade de vivências e interações entre pares, estabelece conexão horizontal com seus agentes. Educadores e estudantes estão em um processo intenso de ensino e aprendizagem, de interação e humanização, de inesgotáveis possibilidades. A Educação é o caminho para a transformação do sujeito, para a interação social e a busca da humanização e, juntamente com ela, a Educação Preventiva Integral, possibilita auxiliar o sujeito para a superação das suas necessidades. Nesse sentido, pode-se afirmar a educação transformadora a partir da realidade do sujeito como ponte para ações impactantes e efetivas em meio àqueles que estão imersos em situações de desigualdades e vulnerabilidades sociais, uma vez que a transformação acontece a partir da práxis.

Crianças e adolescentes, em suas condições reais, estabelecem relações com o meio em que vive e, junto a eles, influenciam e são influenciados. Há a importância de conhecer o processo e o contexto do sujeito para auxiliá-lo em sua construção autônoma, bem como provocar políticas públicas de caráter protetiva, pautadas na proximidade com a realidade: privilegiar fatores de proteção ao invés de reforçar os fatores de risco na infância e adolescência. Faz-se necessário refletir e analisar al- 
gumas fragilidades existenciais, vividos pelos sujeitos na sociedade contemporânea (nos colocando em conflito devido a fragilidade humana). O enfoque nos diversos fenômenos sociais da vida urbana que caracterizam a vida diária cria um sistema doente, de riscos e vulnerabilidades sociais. Por isso, a importância de observar a sua própria condição vulnerável, não apenas do ponto de vista do outro, mas, principalmente, da própria consciência na condição de um sujeito crítico, autônomo e problematizado. Para isso, a educação, na condição de um processo transformador, torna-se o caminho para a construção humana.

A Pedagogia do Oprimido, em sua visão libertadora, humanizadora e problematizadora dos conflitos que geram opressores e oprimidos, poderia ser assumida como um dos textos básicos para se entender e praticar a prevenção de forma efetiva e eficaz. Compreender a infância e a adolescência como processo de desenvolvimento humano, que tem sua prática no contexto da contemporaneidade, provocando o estudo de temas significativos e que evidenciem o diálogo como meio para as reflexões coletivas, problematizando e evidenciando a palavra como caminho ético para se cultivar a cultura das gerações pela paz. A paz se constrói por meio de atitudes diárias, de valores humanos e sociais inseridos no cotidiano escolar. Ela se faz necessária para o desenvolvimento de um ambiente sadio e harmonioso. A paz é ação.

Ressalta-se a importância do estabelecimento de mecanismos nas escolas que priorizem a Educação Preventiva Integral como parte do trabalho pedagógico, integrados aos diversos temas e disciplinas que formam o currículo, enriquecendo assim, a formação e o desenvolvimento humano, dando lugar a valores sociais e interacionais, proporcionando a cooperação, o respeito à diferença e o diálogo. Nesse sentido, entende-se que a educação é o caminho para a humanização e para a prevenção e o diálogo é um dos instrumentos que podemos utilizar como prática pedagógica inicial para levar os estudantes à dialogicidade. A educação preventiva integral é um processo educativo que envolve ações de construção de conceitos éticos e cidadãos, juntamente com os conteúdos programáticos da escola. Nesse sentido, sem dúvida, a noção de empatia é primordial para a formação de comportamentos generosos e solidários.

Ademais, pensar sobre o desenvolvimento humano, sobre infância, adolescência, vai muito além das barreiras acadêmicas, uma vez que, refletindo a/na condição de educadores, deve-se a consciência, o diálogo, em que se faz necessário aprofundar o conhecimento no ser e em suas relações/histórias de vida, para então auxiliar no caminho de Educação Preventiva Integral. Para isso, podem-se elaborar práticas relacionadas à construção da autonomia, da identidade e do in- 
centivo à interação social, para que gradativamente a qualidade de vida melhore. Salientam-se as contribuições do grande educador Paulo Freire, que, com as provocações sobre a reflexão e prática da educação humanizadora, problematizadora, de transformação social, oportuniza a construção de novos conhecimentos e o aprofundamento do olhar a respeito do ser, humano e de suas relações, bem como do panorama de pesquisas envolvendo prevenção e o sujeito em sua totalidade. Com esse trabalho de observar e discutir sobre o ser, a escola e os espaços de interação proporcionam a formação de agentes multiplicadores, de uma postura voltada para a Educação Preventiva Integral.

\section{Nota}

1 O presente trabalho foi realizado com apoio da Coordenação de Aperfeiçoamento de Pessoal de Nível Superior - Brasil (CAPES) - Código de Financiamento 001”.

\section{Referências}

ALMEIDA; Cleide Rita Silvério de; ARONE, Mariangelica. Autoformação, condição humana e dimensão estética. EccoS - Revista Científica, São Paulo, n. 43, p. 97-114, maio/ago. 2017.

ASINELLI-LUZ, Araci. Educação e prevenção ao abuso de drogas: limites e possibilidades. 2000. 166 f. Tese (Doutorado em Educação) - Faculdade de Educação, Universidade de São Paulo, São Paulo, 2000.

ASINELLI-LUZ, Araci. Visão educacional das drogas: orientação para os pais e professores. In: ANDREOLI, Cleverson V.; TORRES, Patrícia Lupion (org.). Complexidade: redes e conexões do ser sustentável. Curitiba: Senar - Paraná, 2014. p. 377-397.

BRONFENBRENNER, Urie. Bioecololgia do Desenvolvimento Humano: tornando os seres humanos mais humanos. Porto Alegre: Artmed, 2011.

CARRARO, Valéria; CURY, Mauro José Ferreira. A Educação da pessoa idosa universitária e a Pedagogia de Paulo Freire. Olhar de Professor, Ponta Grossa, v. 18, n. 1, p. 91-98, 2015.

DESSEN, Maria Auxiliadora; POLONIA, Ana da Costa. A Família e a escola como contextos de desenvolvimento humano. Paidéia, Distrito Federal, v. 17, n. 36, p. 21-32, 2007.

FREIRE, Paulo. Pedagogia da autonomia. 6. ed. Rio de Janeiro: Paz e Terra, 1996.

FREIRE, Paulo. Pedagogia da Indignação: cartas pedagógicas e outros escritos. São Paulo: Unesp, 2000.

FREIRE, Paulo. Pedagogia do oprimido. 6. ed. Rio de Janeiro: Paz e Terra, 1979.

FREIRE, Paulo. Pedagogia do oprimido. 23. ed. Rio de Janeiro: Paz e Terra, 1987. 
LIMA, Tatiane Delurdes de. O educador social e o pedagogo escolar na prevenção do abuso de drogas na adolescência. 2017. 167 f. Dissertação (Mestrado em Educação) - Setor de Educação, Universidade Federal do Paraná, Curitiba, 2017a.

LIMA-BERTON, Tatiane Delurdes de; MONTEIRO, Michelle Popenga Geraim; ASINELLI-LUZ, Araci. O educador e a prática de educação preventiva integral. Quaderns d'Animació $i$ Educació Social, v. 30, p. 1-19, 2019.

LOPES NETO, Aramis Antônio. Bullying: saber identificar e como prevenir. São Paulo: Brasiliense, 2011.

MAGRI, Cledir Assírio. A educação em direitos humanos: uma abordagem a partir de Paulo Freire. Revista Espaço Pedagógico, Passo Fundo, v. 19, n. 1, 2012.

MONTEIRO, Michelle Popenga Geraim. O bullying segundo a percepção dos estudantes do $5^{\underline{ }}$ ano do ensino fundamental. 2017. 148 f. Dissertação (Mestrado em Educação) - Setor de Educação, Universidade Federal do Paraná, Curitiba, 2017b.

MONTEIRO, Michelle Popenga Geraim; LIMA-BERTON, Tatiane Delurdes de; ASINELLI-LUZ, Araci. A infância e a Cultura da Paz na perspectiva da Pedagogia do Oprimido. E-curriculum, São Paulo, v. 16, n. 4, p. 1234-1251, 2018.

MONTEIRO, Michelle Popenga Geraim; LIMA-BERTON, Tatiane Delurdes de; ASINELLI-LUZ, Araci. A escola como expressão da violência ou locus da cultura da paz?. Dialogia, São Paulo, n. 32, p. 65-80, maio/ago. 2019.

PINHEIRO, Paulo Sergio. Relatório Mundial Sobre a Violência contra a Criança. Secretaria Especial dos Direitos Humanos (Trad.). Genebra, Suíça, 2010.

ROMERO, Emilio. Vulnerabilidade humana e conflitos sociais: suas fontes. In: RIBEIRO, W.; ROMERO, E. (org.). Vulnerabilidade humana e conflitos sociais: por uma psicologia social compreensiva. São José dos Campos: Della Bídia, 2009. p. 12-23.

SALLES FILHO, Nei Alberto. Paulo Freire e educação para a paz: o mesmo sentido. In: CONGRESSO NACIONAL DE EDUCAÇÃO - EDUCERE, 9. Anais [...]. Curitiba: PUCPR, 2008.

SALMIVALLI, Cristina. Participant role approach to school bullying: implications for interventions. Journal of Adolescence, v. 22, p. 453-459, 1999.

SALMIVALLI, Cristina. Bullying and the peer group: a review. Aggression and Violent Behavior, v. 15, p. 112-120, 2010.

SALMIVALLI, Cristina. Participant roles in bullying: how can peer bystanders be utilized in interventions? Journal of Theory into Practice, n. 53, p. 286-292, 2014.

SANTOMÉ, Jurjo Torres. Globalização e interdisciplinaridade. O currículo integrado. Porto Alegre: Artes Médicas, 1998.

TOGNETTA, Luciene Regina Paulino. A formação da personalidade ética: estratégias de trabalho com afetividade na escola. Campinas: Mercado das Letras, 2013.

TRILLA, Jaume; GHANEM, Elie. Pontuando e Contrapondo. In: TRILLA, Jaume; GHANEM, Elie; ARANTES, Valéria Amorim (org.). Educação formal e não-formal: pontos e contrapontos. São Paulo: Summus, 2008. p. 13-55. 